\title{
Medication Safety
}

\author{
Hooi Cheng Soon, Pierangelo Geppetti, Chiara Lupi, \\ and Boon Phiaw Kho
}

\subsection{Introduction}

Ensuring patient safety during health services delivery is fundamental for an efficient healthcare system [1]. A strong organisational culture of patient safety and quality enables service providers to be better prepared for health emergencies, promote healthier populations and contribute to the achievement of universal health coverage [2].

Pharmacotherapy is the most common therapeutic intervention in healthcare to improve health outcomes of patients. Despite the intent to benefit patients, there are many instances where effectiveness of medications is undermined by poor medication use process and practices that could promote avoidable medication errors, thus putting patients' health in jeopardy [2]. Safe care

H. C. Soon

Department of Pharmacy, Kulim Hospital, Kedah, Malaysia

P. Geppetti $(\bowtie) \cdot$ C. Lupi

Pharmacology and Oncology Unit, Department of Health Sciences, University of Florence,

Florence, Italy

Headache Centre, Careggi University Hospital, Florence, Italy

e-mail: pierangelo.geppetti@unifi.it;

chiara.lupi@unifi.it

B. P. Kho

Department of Pharmacy, Sarawak General Hospital,

Sarawak, Malaysia requires that all individuals, patients and care providers are protected from medication-related harm when using the essential health services they need. A medication error is defined by the United States National Coordinating Council for Medication Error Reporting and Prevention as "Any preventable event that may cause or lead to inappropriate medication use or patient harm while the medication is in the control of the health care professional, patient, or consumer. Such events may be related to professional practice, health care products, procedures, and systems, including prescribing, order communication, product labelling, packaging, and nomenclature, compounding, dispensing, distribution, administration, education, monitoring and use" [3].

Unsafe medication practices leading to medication errors are among the leading causes of morbidity and mortality in health services delivery. A medication safety fact file released by the World Health Organization (WHO) in 2019 shows that medication errors harm millions of patients yearly [4]. The resultant financial burden of harm was estimated at USD42 billion each year, representing approximately $1 \%$ of global expenditure on health [5]. More importantly, these errors are preventable. Identifying the causes of errors and building safeguards in the healthcare system are key steps towards providing safe, quality, people-centred, timely, equitable, efficient and integrated health services. 


\subsubsection{A Focus on Transitions of Care, Polypharmacy and High-Risk Situations}

Medication errors often occur as a result of gap in medication use process and practice, from prescribing and ordering to transcribing and/or documenting, and from preparing and dispensing to administering and monitoring. Transition points of care, such as admissions to hospital from a community or primary care setting, transfer from one area within the hospital to another or discharge from hospital to another care setting, are particularly vulnerable to medication errors [2]. Moreover, medications prescribed can be contraindicated for a particular patient, or in combination with his or her concomitant medications. The risk of harm is further heightened in highrisk situations associated with the use of highrisk medications.

The available evidence indicates that a substantial amount of medication-related harm is focused on transitions of care, polypharmacy and high-risk situations. In March 2017, the WHO launched the third Global Patient Safety Challenge: Medication Without Harm with the goal of reducing the risk of severe avoidable medication-related harm by $50 \%$, over 5 years, globally [2]. It was envisioned that when these areas are appropriately managed, the risk of avoidable harm to many patients could be reduced, leading to improved patients' trust towards the healthcare system, as well as healthcare workers' job satisfaction, ultimately achieving safer hospital and primary care.

\subsubsection{Learning Objectives}

This chapter aims to highlight inherent risks and weaknesses in the medication use process in healthcare facilities, focusing on the three main areas identified as having the greatest burden of harm, as well as on the strategies that can be applied to mitigate them. After completing this chapter, readers will be able to appreciate the prevalence and incidence of common medication safety issues, as well as approaches that can be employed to reduce avoidable medication-related harm associated with transitions of care, polypharmacy and high-risk situations. As health service delivery requires inter-disciplinary involvement, this chapter also aims to engage and empower young or experienced students or residents from different specialties to work together in ensuring medication safety while delivering health services.

\subsubsection{Learning Outcomes: Knowledge and Performance}

\subsubsection{Knowledge Requirements}

At the end of this chapter, a health professional should know:

- The relationship between medication errors and adverse drug events (ADEs).

- The scale of medication errors at three priority areas of medication safety.

- Common points in the medication use process where errors can take place.

- Ways to ensure medication safety at three priority medication safety areas.

- The benefits of inter-professional approach.

\subsubsection{Performance Requirements}

Healthcare professionals who understand that medication errors are preventable harm and appreciate risks of unnecessary harm associated with the three priority areas of medication safety will strive to:

- Improve quality and availability of information during transitions of care.

- Engage with and educate patients, families and caregivers.

- Carry out medication reconciliations.

- Perform medication reviews.

- Practice deprescribing.

- Use generic names.

- Be extra vigilant during high-risk situations or treating high-risk patients with high-risk medications.

- Understand and practice drug calculations, e.g. adjustments of dosage based on clinical parameters. 
- Be familiar with the medications prescribed, prepared, dispensed, and/or administered.

- Develop double-check habits.

- Appreciate human limitations and human factors as contributing factor of errors.

- Communicate clearly and be an effective team player.

- Report and learn from errors.

\subsection{Medication Safety in Transitions of Care}

Transitions of care involve movement of patients between different levels of care within the same setting or across settings, and consultations with different healthcare providers (see Fig. 31.1). Transitions of care may also involve other care providers, such as palliative care or social care. During transitions of care, changes to the current medication list of patients are very likely to occur. Therefore, ensuring medication safety involves implementation of safe medication practices to bridge critical communication gaps in medication use process. These could include appropriate prescription and risk assessment, medication review, patient engagement and communication, as well as medication reconciliation [6]. Figure 31.1 shows the medication use process for a patient within the same setting or across different levels of care, specifically at the interface between hospital and primary care.

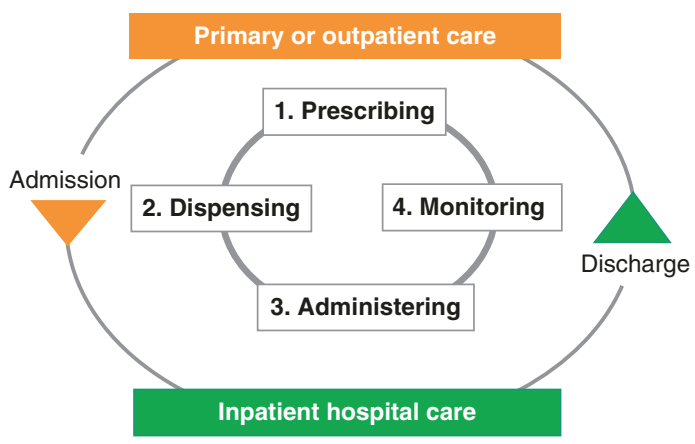

Fig. 31.1 Medication use process and communication during transitions of care

\subsubsection{Prevalence of Medication Discrepancies}

For patients who receive multiple medications from varied prescribers across different settings, obtaining a single medication list or a "gold standard" on what they should be taking can pose a significant challenge [7]. This invariably predisposes patients to a "mismatch" of the medications they take on a regular basis and what is prescribed to them at points of care, such as upon admission or at discharge. Technically, the use of the term "medication discrepancy" will be more appropriate than the term "error" when referring to the "mismatch", in efforts to capture potential medication errors that occur during transitions of care [7]. Medication discrepancy is, therefore, defined as "Any difference between the medication use history and the medication orders. Discrepancies may be intentional, undocumented intentional or unintentional discrepancies" [6].

The prescribing process, from starting a new medication, adding, withholding or stopping a medication, to alteration of dosages by prescribers when patient receives outpatient care or inpatient care, could lead to confusion among subsequent care providers (e.g. primary care counterparts and pharmacists). For instance, when reasons for changes in the preadmission medication list are not reported in the patient's discharge medication list, the next care providers have to conjecture to determine the rationale of these alternations, and whether the change is temporary or permanent [8]. Medication discrepancies owing to changes in medications during hospital admission can be intentional, attributed to the condition which caused the admission or unrelated to the reason for hospitalisation, such as to improve the management of existing chronic illnesses. Importantly, any undocumented intentional or unintentional medication discrepancy is a safety risk to patients. Studies indicate that more than half of patients experienced at least one unintended medication discrepancy during admission [9, 10]. One national multi-site audit found that nearly half of the patients with at least one new medication started had undocumented reason, while more 
than half of the cases with medication discontinued or withheld had undocumented reason. In addition, three out of ten patients had unintentional omissions of preadmission medication [11].

\subsubsection{Medication-Related Harm During Transitions of Care}

Prevention of medication-related harm for patients who seek hospital or primary care, including during transitions of care, is a top patient safety priority. While not all medication discrepancies occurring at transitions of care cause immediate patient harm, unidentified and unresolved discrepancies can increase the risk of ADEs, emergency department visits and hospital readmissions in the longer time frame, such as at 30-day time interval. A systematic review showed that $11-59 \%$ of medication discrepancies that occurred at transition points can lead to these outcomes [10]. In fact, about $33.3 \%$ of ADEs that led to hospital admission were attributable to preventable medication errors [12, 13]. Omission errors at discharge can also prove to be detrimental. For instance, myocardial infarction can be attributed to the failure to continue aspirin for secondary prevention during care transition. Such risks are further heightened for patients with low health literacy, as well as for those prescribed with high-risk medications or complex medications regimens. ADE is defined as:

Any injury resulting from medical interventions related to a drug. This includes both adverse drug reactions that are not preventable and complications resulting from medication errors, which are preventable $[6,14]$.

\subsubsection{Making Medication Use Safer During Transitions of Care}

Ensuring medication safety during transitions of care often require a multifaceted systematic approach involving inter-disciplinary care teams such as doctors, pharmacists and nurses. Interventions with the goal of reducing medication-related harm during transitions of care focus on three essential areas:

- Medication reconciliation

- Information clarity and availability at all transition of care points

- Patients and family engagement and education

\subsubsection{Medication Reconciliation}

Medication reconciliation is a risk mitigation strategy for preventing ADEs. It is defined as "The formal structured process in which healthcare professionals partner with patients to ensure accurate and complete medication information transfer at interfaces of care" [6]. Medication reconciliation is an important component in health services delivery especially for patients during hospitalisation. The best possible medication history (BPMH) is obtained when information about all medications taken by a patient is recorded accurately. This is often carried out via interview of patients, their families or caregivers using a structured format. Obtaining BPMH followed by reconciliating the medication lists during transitions of care is essential to ensure medication safety and continuity of care, with the goal of communicating accurate and complete medication information to patients and subsequent care providers (Table 31.1).

Obtaining BPMH and carrying out medication reconciliation can take up to $30 \mathrm{~min}$ per patient [13]. Implementation of formal and structured medication reconciliation processes requires education and training of all healthcare professionals involved, including prescribers, nurses, pharmacists, and pharmacy technicians. Roles and responsibilities of each team member should be clearly elucidated and agreed upon. Targeting high-risk patients has the highest impact in contributing to the success of intervention, whereas having technologies and appropriate tools that aid standardisation could force completion of these processes [15]. The High 5s Project is a WHO initiative to standardise medication reconciliation processes to improve patient safety. Apart from reducing 
Table 31.1 Steps in the medication reconciliation process to ensure medication safety during transitions of care $[6,13]$

\begin{tabular}{|c|c|c|}
\hline & On admission & On discharge/transfer \\
\hline Verification & $\begin{array}{l}\text { Verifying the information obtained } \\
\text { from patient/caregivers against at least } \\
\text { one reliable source of information. }\end{array}$ & $\begin{array}{l}\text { Retrieving the BPMH (or completing this if it was not } \\
\text { completed upon admission) and verifying the final } \\
\text { medication list at the time of discharge or transfer. }\end{array}$ \\
\hline Clarification & $\begin{array}{l}\text { Returning to the patient and confirming } \\
\text { the medication list with patient to build } \\
\text { the BPMH. }\end{array}$ & $\begin{array}{l}\text { Clarifying any inappropriate dosages or frequency and } \\
\text { whether the change is temporary or permanent. }\end{array}$ \\
\hline Reconciliation & $\begin{array}{l}\text { Reconciliating the BPMH with the } \\
\text { medications prescribed on admission to } \\
\text { identify and resolve any discrepancies. }\end{array}$ & $\begin{array}{l}\text { Reconciliating and deciding which medication is } \\
\text { required after discharge or transfer and prescribing or } \\
\text { listing it. }\end{array}$ \\
\hline Documentation & $\begin{array}{l}\text { Documenting reasons for intentional } \\
\text { discrepancies and updating records. }\end{array}$ & $\begin{array}{l}\text { Documenting reasons for changes or discontinuations } \\
\text { to preadmission medication list and updating records, } \\
\text { to indicate the discharge medication list and changes. }\end{array}$ \\
\hline
\end{tabular}

potential medication-related harm, one of the lessons shared in the High 5s Project on implementing medication reconciliation is that discrepancies that are resolved soon after admission will reduce delays in discharge and risk of human factor-related medication error [13].

\subsubsection{Information Clarity and Availability at All Transition of Care Points}

As mentioned earlier, BPMH is an important patient document for transitions of care. Hospitals and primary care teams should work together in a complementary manner to build the BPMH, and both patients and healthcare professionals should have access to an up-to-date medication list to ensure continuity of care [16]. Various facilitating tools and technologies described below are now available to ensure information availability and clarity during transitions of care.

\section{Appropriate Tools and Technology}

Having a checklist and form to standardise each stage of medication reconciliation processes can be helpful in improving medication safety, and an added benefit of this intervention is that it is feasible also in low resource settings. The form (either in paper format or a simple electronic format) should be designed to enable listing of all current medications and have a space to communicate changes in therapy, whether addition or discontinuation, temporary or permanent, with rationale clearly stated $[16,17]$.

\section{Electronic Health Records (EHRs)}

EHRs are electronic versions of paper charts, which record patient information. A wellfunctioning EHR system improves the clarity and timeliness of medication information during transitions of care. While there has been steady growth in the adoption of EHRs globally, many are not integrated across or within settings, complicating the seamless transfer of information. Apart from sufficient funding, other major barriers include poorly developed infrastructures and communication technologies to support EHR systems, as well as the lack of human resources and capacity to develop and maintain such complex systems [18]. The discharge summary records should reflect the medication usage of the patient across transitions, as well as be accessible and editable by appropriate healthcare personnel [6]. When EHR and welldesigned tools are available, up to a $45 \%$ reduction in unintentional discrepancies, improved patientprovider communication, optimisation of medication regimen and better patient medication adherence to treatment are achievable $[19,20]$.

\section{Information to Support Safe Use of Medications}

Promoting the use of the generic name (international non-proprietary name) of medicines in the prescribing and labelling process will help to improve clarity for both patients and healthcare professionals alike and minimise reconciliation errors. In addition, national pharmacovigilance centres, pharmacies or medication information services can improve understanding as well as 
support safe and effective use of medication by providing readily accessible information on medications and potential ADE for both patients and healthcare professionals.

\subsubsection{Patient Engagement and Education}

Navigating the complicated processes in transitions of care, especially across settings, requires high level of health literacy and active involvement from patients and their families or caregivers [21-23]. This is essential as they are the only constant in their respective healthcare journeys, and those with low health literacy will face challenges to identify and voice discrepancies in their medication list during care transitions.

As being inadequately educated regarding their medications increases the risk of ADEs or suboptimal therapy, various actions can be taken by healthcare professionals to engage and educate patients. For starters, healthcare professionals should ensure that all patients as well as their immediate families or caregivers are made aware of changes in their medication, the monitoring needs and whom to contact should problems arise during transitions of care [13]. This can be done by properly engaging and counselling them, especially during discharge from hospitals, including asking whether they understand what is being communicated.

Other strategies include developing standardised discharge instructions for patients, creating or updating patient-held medication list with rationale for changes in therapy stated and follow-up needs specified. This comprehensive medication list can also increase their understanding about their medical conditions as well as the indication of each medications, how to take them, what side effects to expect and when they should seek help.

\subsubsection{Monitoring and Measurement}

Successful implementation of transitions of care interventions requires extensive coordination and communication between healthcare providers from different institutions. Various interventions can be put to trial to improve transitions of care, but they have to be adequately monitored and measured to determine their efficacy in reducing medication discrepancies and avoidable patient harm. Various standardised outcome measures are available, for instance process measures for the quality and effectiveness of medication reconciliation such as outstanding unintentional medication discrepancies and percentage of patients receiving medication reconciliation [13]. In addition, validated survey instruments for patient-centred measures, such as patient experience and understanding of medications, are also recommended to achieve a well-rounded evaluation [16, 24, 25].

\subsection{Medication Safety in Polypharmacy}

In order to have a rough estimate of the prevalence of polypharmacy, it is necessary to understand the definition of polypharmacy first. In its most simplistic definition, polypharmacy means "an individual on multiple medications" [26, 27]. This usually afflicts those with numerous chronic health conditions, and is highly prevalent in the elderly as the number of co-morbidities increases in tandem with age [28, 29]. Individuals with polypharmacy often consult more than one medical specialist and have prescription medications filled at multiple pharmacies, making their medication regimen complex. This is further complicated by usage of non-prescription as well as traditional and/or complementary medications [28].

There is however no exact definition for polypharmacy. It is often defined as taking five or more medications, but other numbers were also used as the cut-off point [30]. This numerical definition is criticised as being arbitrary, as the number of medications taken lacks correlation with patients' clinical outcome. In fact, the use of multiple medications is warranted and rational in some health conditions, for example, heart or renal failure. This rational polypharmacy is contrary to the negative connotation associated with the term, where it is used to describe duplication of therapy, presence of drug interaction, nonindicated or excessive use of medicines [31, 32]. Hence, proponents now advocate for a distinction 
to be made between appropriate and inappropriate polypharmacy $[31,32]$.

For polypharmacy to be appropriate, the combination of medicines prescribed has to be optimised based on available best evidence and incorporates the patient's wishes to achieve the intended clinical outcomes [26, 33]. Failure to do so will result in inappropriate or problematic polypharmacy, where the risk of therapy outweigh the intended benefit, resulting in suboptimal treatment or patient harm. This includes potential prescribing omissions, where polypharmacy paradoxically results in under-prescribing of indicated medications due to an aversion towards potential ADR and non-adherence [33].

\subsubsection{Prevalence of Polypharmacy}

Most prevalence studies focused on the number of medicines, as well as frequency of potentially inappropriate medications (PIM) [34, 35]. Polypharmacy is usually defined as $\geq 5$ medications, while the term excessive polypharmacy is used for $\geq 10$ medications. Most of the research on polypharmacy focuses on the elderly (aged $\geq 65$ years old), those living in managed care facilities and cancer patients, as these populations are more prone and vulnerable to the consequences of inappropriate polypharmacy. In the elderly population, a systematic review noted that those in primary care recorded a lower prevalence of patients having $\geq 5$ medications at $27-59 \%$ compared to those who are hospitalised at 46-84\% [35]. A study conducted across Europe established that one-third of community dwelling patients were on polypharmacy [36]. Rates of excessive polypharmacy were also reported, with around $10 \%$ of patients falling within this group [35, 37]. In long-term care facilities, 38-91\% were on $\geq 5$ medications, whereas $11-65 \%$ were on $\geq 10$ medications [38].

\subsubsection{Medication-Related Harm in Polypharmacy}

The concern with polypharmacy that makes it a medication safety priority is that it increases the risk of adverse drug reactions (ADRs) due to drug-drug interactions and duplicity of therapy. These unwanted effects are a major source of iatrogenic medication-related harm for patients, and the elderly are more susceptible due to agerelated physiologic decline [31, 39]. An adverse reaction can also result in a prescription cascade, where it is mistaken for an emerging medical condition and treated with new medicines [29]. These situations contribute to the incidence of intentional or non-intentional non-adherence among patients, as well as physical harm such as falls, fractures, cognitive impairments and dementia $[29,40]$. In terms of economic implications, polypharmacy increases avoidable healthcare costs such as emergency department visits and hospitalisations [40, 41].

The main cause of polypharmacy is the emergence of multiple morbidities in an ageing population. The prevalence of having two or more chronic conditions increases with age, afflicting two-thirds of those aged more than 65 years old [42]. Multiple morbidity is a major confounder of the relationship between number of medications and health outcomes [43]. Other patient factors affecting polypharmacy include gender, with females having a greater preponderance to take more medications, ethnicity, and socioeconomic status, with those of poorer background and less education more prone to polypharmacy $[34,37,44]$.

Health system changes causing an increase in polypharmacy include improved patient awareness and availability of treatment, wider insurance coverage, as well as pharmaceutical promotions [45, 46]. The rise of preventative medicine also contributes to polypharmacy, as patients are prescribed medicines to reduce their probability of being inflicted with stroke or acute myocardial infarctions [26]. Emphasis on evidence-based practice also results in the routine application of clinical guidelines in prescriptions. Unfortunately, these guidelines are often single condition specific and do not cater to potential medication-related problems due to treatment of multiple morbidities, further increasing the number of medications and potentially inappropriate medications being prescribed $[26,29,40]$. 
The number of medicines itself, regardless of appropriateness, also constitutes a risk for ADR as it increases the odds of drug interaction and inappropriate prescription $[37,40]$. For example, the combined use of diuretics and blood pressure medications in a patient with heart failure can lead to postural hypotension and hyponatremia. Interactions can also occur with non-prescription medicines, complementary and alternative medicines as well as food [34]. In fact, the addition of a new medication in a patient with polypharmacy was found to elevate the risk of prescribing or monitoring error by $16 \%$ [27]. Prevalence of potential inappropriate medications meanwhile was found to range from $27 \%$ to $56 \%$ among the elderly in clinical care [35].

\subsubsection{Approaches for Addressing Polypharmacy}

Ensuring medication safety in polypharmacy entails the optimisation of medicines use, in which medicines prescribed for a patient are indicated and well considered in terms of their risk and benefit profiles, potential interactions and patient acceptability. Various interventions aimed at improving the appropriate use of polypharmacy had been carried out, but systematic reviews concluded that these interventions had yet to demonstrate significant clinical outcomes [33, 47]. However, this is more likely caused by deficiencies in the research designs rather than actual ineffectiveness of the interventions in the trials. Most of the studies also follow-up their subjects for less than 1 year, which may not be enough to detect significant changes in clinical outcomes.

Interventions were led by doctors, pharmacists or multidisciplinary endeavours, and involved structured pharmaceutical care programme, educational intervention and training, medication review, medication screening, prescription review, electronic medical record-based intervention, comprehensive geriatric assessment and multidisciplinary case conference [33, 47]. Some of the more established strategies are further discussed below.
For patients living in nursing homes or aged care facilities, similar multifaceted interventions were employed to optimise medications use. Medication review was the main recurring component along with multidisciplinary case discussion, education for staff, and utilisation of clinical decision support system [48]. Other interventions suggested include (1) implementing a medication reconciliation service by pharmacists, (2) conducting audits on high-risk medication use, (3) developing deprescribing scripts, (4) developing prescribing guidelines for geriatric patients with multiple co-morbidities, (5) making electronic medication charts and records accessible to all healthcare professionals, and (6) empowering facility level Medication Advisory Committee to determine medication appropriateness [49].

\subsubsection{Measuring Appropriateness of Medications}

In order to ensure medication safety in polypharmacy, medications taken by a patient, especially those with multiple morbidities, should always be assessed by physicians before the start of a new medication, or routinely by pharmacists during medication review and reconciliation [50]. The aim of this assessment is to increase medication appropriateness and decrease inappropriately prescribed medication and prescribing omissions.

Among the elderly, the Beers criteria is often used to determine appropriateness of medicines use [51]. Medicines that should generally be avoided in this population or in certain specific medical conditions are considered. A total of 48 medicines are deemed inappropriate to be used among the elderly, including benzodiazepines, anticholinergics and antihistamines, long-term non-steroidal anti-inflammatory drugs and stimulation laxatives. Other validated screening tools include Medication Appropriateness Index (MSI) and Screening Tool of Older Persons' Prescriptions and Screening Tool to Alert Doctors to Right Treatment (STOPP/START) [26]. Burt et al. developed a 12-item measure of polypharmacy appropriateness based on a systematic review and expert panel consensus, adding in measures on determinants of patient adherence, 
medication regimen complexity and nonpharmacological treatments [52].

\subsubsection{Medication Reviews}

Medication review is the foremost strategy to reduce polypharmacy. In medication reviews, patients' medications are evaluated by a trained healthcare professional and discussed together to identify drug-related problems. Interventional recommendations are then made to optimise treatment [41, 53, 54]. In 2018, the Scottish National Health Services published a comprehensive seven-step review process to serve as guidance in managing polypharmacy in a patientcentred manner. It involves (1) establishing treatment objectives with the patient, before working through the whole list of medications to determine drug therapies that are (2) essential as well as (3) potentially unnecessary. The current treatment is then assessed to determine its (4) effectiveness, (5) safety, (6) cost-effectiveness and (7) patient acceptance [50].

Medication reviews are often led by pharmacists, where other issues such as medication adherence, device use technique and monitoring of treatment are also considered [53, 54]. This service is available in most Western countries, including the United States, United Kingdom, Australia, Canada and New Zealand, and is often conducted in community pharmacies and reimbursable by the respective governments [54]. Outcome wise, medication reviews that are more comprehensive and conducted in the context of patients' clinical condition were found to significantly reduce hospitalisation [53]. Medication reviews with follow-up were also found to improve patients' quality of life, reduce medication-related hospitalisations and to be cost-effective $[55,56]$. In the United States, medication reviews known as Medication Therapy Management (MTM) were found to improve medication appropriateness, adherence and hospitalisation for diseases such as heart failure and diabetes [57].

For a patient with polypharmacy, there is an increased risk of discrepancies during transition of care between different institutions. Hence conducting medication reviews and reconciliations during hospital admission and upon discharge are likely to have a high impact on medication safety. A mechanism has to be in place to ensure changes in medication are properly documented and conveyed to the receiving care team, as this vital information is often inaccurate or lacking [26, 27].

\subsubsection{Rational Prescribing}

Several guidelines on prescribing for the elderly exist, especially for conditions often affecting them such as management of constipation, chronic pain and rational usage of benzodiazepines, anticholinergics and anti-psychotics [50]. Guidelines for the management of patients with multiple chronic conditions are also being developed and this is the way forward for the management of polypharmacy [27]. Such guidelines are currently lacking, with only eight being identified by a systematic review [58]. Tools to assist in decision-making on polypharmacy are also available, for example, the Medicines Effectiveness Summary, where the annualised numbers needed to treat (NNT) to achieve a beneficial outcome for high-risk medications were calculated based on available trial evidence [50].

Computerised decision support systems are also increasingly being adopted to tackle polypharmacy. This includes assisted detection of inappropriate medicines and doses, which are then conveyed to prescribers via an alert system. This intervention has been found to modestly reduce ADEs [37]. PRIMA-eDS, a recently developed European-based electronic decision support system, is able to recommend medication discontinuation or modification based on patients' data and latest guidelines [59].

\subsubsection{Deprescribing}

Deprescribing entails going through a patient's medication list systematically to identify items that can be safely discontinued. It includes identifying the rationale of each previously prescribed medication, weighing the benefit of the regimen against risk of ADEs, assessing their potential to be discontinued, prioritising the discontinuation sequence, as well as monitoring the effect on patient care [60]. Due diligence is important in 
deprescribing, as inappropriately stopping a medication can lead to adverse drug withdrawal events. For these medications, a gradual tapering of doses is recommended [44]. Research findings suggested that deprescribing saves cost, reduces waste of medications and does not result in patient harm; however definitive impact on clinical outcomes as well as patients' medication adherence cannot be determined due to paucity of high quality, long-term trials [61, 62].

\subsubsection{Health System Changes}

In order to develop polypharmacy management programmes that are sustainable, change management principles such as Kotter's Eight step process for leading change, as well as implementation strategies that are grounded in established theories are recommended [41]. Multidisciplinary and multinational projects, engaging varied stakeholders including politicians, healthcare commissioners, educators, regulators, providers, and patients, such as the European Union's SIMPATHY consortium are also essential to spur innovation and drive change management [63].

\subsubsection{Practical Tips}

In addition to institutional changes, healthcare professionals can also address polypharmacy according to their individual capacities. The King's Fund (2013) suggested practical tips on polypharmacy management that can be carried out by all healthcare providers [26]. Tips include ensuring that medication regimens are as simple as possible for patients in terms of frequency and pill burden, for example, substituting rather than adding medications to the regimen. Making things easier is also recommended, such as providing clear and specific written instructions, dosing schedules, compliance aids as well as assessing their level of understanding.

\subsubsection{Practicing Patient-Centred Care}

The involvement of patients and their family members in shared decision-making on their treatment regimen is important to ensure medication safety in polypharmacy. Prescribers should always communicate with patients to ensure that their needs are met and concerns addressed. Involvement of patients is essential to ensure that they understand the medication regimen and will adhere to the medicines prescribed $[26,50,52]$. Tools to facilitate patient involvement can be used, including patient-held medication records, explanation materials for illnesses and medications as well as empowerment support materials such as WHO's 5 Moments for Medication Safety [41].

\subsection{High-Risk Situations in Medication Safety}

Regarding medication safety, high-risk situations are circumstances which are associated with significant harm due to unsafe medication practices or medication errors [64]. The inherent risk of use of certain drugs, defined as high-risk or highalert medications, as well as certain work environments (e.g. hospital healthcare) and clinical scenarios (e.g. emergency and anaesthesia settings), which involve particular difficulties for healthcare professionals in complying with safe medication practices, represent some examples of high-risk situations. Similarly, there are also some conditions inherent to the individual, such as childhood and old age, and medical conditions, such as hepatic or renal impairment and cardiac failure, which predispose patients to an increased risk of medication errors and ADRs [64]. Pregnant women can even be included among high-risk patients due to the limited information about the safety of most medications in this population, because of a lack of randomised clinical trials [65]. High-risk situations, as a whole, require mechanisms to prevent medication errors and, in case they occur, should cover means of identification before they result in harm to the patient. In a recent consensus prioritisation exercise, a group of leading researchers in patient and medication safety, including experts from the WHO Global Patient Safety Network, identified development of guidelines and standard operating procedures for high-risk medications, patients 
and contexts, as well as the production of scorebased approaches to predict high-risk situations as top priority research areas [66].

\subsubsection{Medication Errors and Related Harm in High-Risk Situations}

\subsubsection{High-Risk Medications}

High-risk medications are drugs that are more likely to cause harm to a patient when they are used in error or taken inappropriately. Although mistakes may or may not be more common with these drugs, the consequences of an error at any level of their management (i.e. prescription, storage, dispensing, preparation, administration and monitoring) are more devastating to patients compared to non-high-risk medications [67]. These medicines require particular attention in the medication use process, mainly because of their potential toxicity, low therapeutic index or high possibility of pharmacological interactions.

A recent systematic review, which focused on the epidemiology of prescribing errors with highrisk medications in the inpatient setting, highlighted that the prevalence of these errors was highly variable, ranging from 0.24 to 89.6 errors per 100 orders. This wide range reflected the lack of uniqueness on definitions of both prescribing errors and high-risk medications. Dosage errors, incorrect date of prescription, and omissions of required medications were the most common prescribing errors. Opioids and sedatives were the most frequent pharmacological categories associated with these errors [68]. In another systematic literature review aimed at defining highrisk drug classes, methotrexate and warfarin were the top two drugs resulting in fatal medication errors [69].

While the drugs identified as high-risk may vary between countries and healthcare settings in light of the types of molecules used and patients treated, analysis of incident data and review of the literature identified a group of medicines that should universally be considered as high-risk. In 2015, the New South Wales Clinical Excellence
Commission summarised these drugs by the mnemonic acronym "A PINCH" (anti-infective agents, potassium and other electrolytes, insulin, narcotics and other sedatives, chemotherapeutic and immunosuppressive agents, and heparin and anticoagulants) [70]. The most frequent medication errors and ADRs associated with the use of the high-risk medication categories considered in "A PINCH" are reported in Table $31.2[64,70]$.

This list is not intended to be exhaustive, and tables should be developed locally in order to reflect the specificities of drugs used in different work environments. A wider list has been drawn up and is periodically updated by the Institute for Safe Medication Practices (ISMP), based on error reports submitted to the ISMP National Medication Errors Reporting Program, evidences from the literature and inputs from practitioners and safety experts. High-risk medications have been classified according to their different use in acute care, ambulatory healthcare and long-term care settings [71].

\subsubsection{High-Risk Patients}

Data from observational studies indicate that $5-27 \%$ of all paediatric medication orders resulted in error [72]. Children, especially neonates and infants, are particularly vulnerable to patient safety concerns, including the use of weight-based dosing, the need for stock medicine dilution to administer small amounts of medication, immature hepatic and renal systems and the inability to self-administer medications or communicate side effects [73].

In the elderly, as discussed in the previous section, long-term polypharmacy due to the emergence of multiple chronic morbidities and high probability of drug-drug interactions are the most critical factors in the medication safety field. It is also noteworthy that the elderly are generally poorly compliant to therapy and less likely to tolerate drugs. Indeed, age-related physiological changes, including the reduction of glomerular filtration rate, the decreasing liver volume and blood flow, as well as an increase of gastric acidity, affect pharmacokinetic processes, 
Table 31.2 High-risk medication list $[64,70]$

\begin{tabular}{|c|c|c|}
\hline High-risk medication groups & Examples of medications & $\begin{array}{l}\text { Examples of medication errors and adverse } \\
\text { drug reactions }\end{array}$ \\
\hline \multirow[t]{2}{*}{ A: Anti-infective } & Amphotericin & $\begin{array}{l}\text { Dosage and administration errors (e.g. } \\
\text { substitution of the lipid-base form with a } \\
\text { high dose of the cardiotoxic conventional } \\
\text { form) }\end{array}$ \\
\hline & Aminoglycosides & $\begin{array}{l}\text { Dosage and monitoring errors (e.g. } \\
\text { dose-related damage to hearing and } \\
\text { kidneys) }\end{array}$ \\
\hline $\begin{array}{l}\text { P: Potassium and other } \\
\text { electrolytes }\end{array}$ & $\begin{array}{l}\text { Injection of potassium, magnesium, } \\
\text { calcium, hypertonic sodium chloride }\end{array}$ & $\begin{array}{l}\text { Preparation and administration errors (e.g. } \\
\text { intravenous infusions incorrectly prepared, } \\
\text { concentrated solutions administered in place } \\
\text { of diluted solutions) }\end{array}$ \\
\hline I: Insulin & All insulins & $\begin{array}{l}\text { Dosage and administration errors (e.g. } \\
\text { incorrect use of non-insulin syringes, } \\
\text { misunderstanding of doses expressed in U } \\
\text { or UI for units) }\end{array}$ \\
\hline $\begin{array}{l}\text { N: Narcotics and other } \\
\text { sedatives }\end{array}$ & $\begin{array}{l}\text { Opioids (e.g. hydromorphone, } \\
\text { oxycodone, morphine, fentanyl), } \\
\text { benzodiazepines (e.g. diazepam, } \\
\text { midazolam), short-term anaesthetics } \\
\text { (e.g. thiopentone, propofol) }\end{array}$ & $\begin{array}{l}\text { Prescribing, dosage and administration } \\
\text { errors (e.g. cardiorespiratory toxicity due to } \\
\text { overdosing, incorrect management of } \\
\text { molecules with different durations of action, } \\
\text { incorrect use of opioid analgesic patches) }\end{array}$ \\
\hline \multirow[t]{2}{*}{$\begin{array}{l}\text { C: Chemotherapeutic } \\
\text { agents }\end{array}$} & Oral and parenteral chemotherapeutics & $\begin{array}{l}\text { Dosage and monitoring errors (e.g. toxicity } \\
\text { due to overdosing) }\end{array}$ \\
\hline & Methotrexate & $\begin{array}{l}\text { Administration errors (e.g. overdosing } \\
\text { induced by daily administration instead of } \\
\text { weekly administration) }\end{array}$ \\
\hline $\begin{array}{l}\text { H: Heparin and } \\
\text { anticoagulants }\end{array}$ & $\begin{array}{l}\text { Low molecular weight heparins (e.g. } \\
\text { enoxaparin), orally active vitamin K } \\
\text { antagonists (e.g. warfarin), newer oral } \\
\text { anticoagulants (e.g. rivaroxaban) }\end{array}$ & $\begin{array}{l}\text { Dosage and monitoring errors (e.g. risk of } \\
\text { inefficacy due to underdosing, risk of } \\
\text { bleeding due to overdosing) }\end{array}$ \\
\hline \multirow{2}{*}{$\begin{array}{l}\text { Other high-risk } \\
\text { medications identified at } \\
\text { Local Health District/ } \\
\text { Facility/Unit Level }\end{array}$} & Paracetamol & $\begin{array}{l}\text { Dosage errors (dose-related liver failure } \\
\text { mainly in children) }\end{array}$ \\
\hline & Non-steroidal anti-inflammatory drugs & $\begin{array}{l}\text { Prescribing errors (long-term } \\
\text { gastrointestinal, renal and cardiovascular } \\
\text { toxicity mainly in high-risk populations) }\end{array}$ \\
\hline
\end{tabular}

thus exposing older people to an increased risk of ADRs [74].

Recent studies have reported that medication use is common among pregnant women. In a multinational web-based European study conducted in pregnant women and new mothers with a child less than 1-year-old, $28 \%$ of the women used medications classified as risky to the foetus or child. Having a chronic disorder was the factor with the strongest association with the use of risky medications during pregnancy [75]. Even fragile patient groups, such as those with chronic pain conditions, diabetes, cancer or major psychiatric disorders, need to be included among patients at increased risk of ADRs.

\subsubsection{High-Risk Contexts}

Two systematic reviews reported that prescribing errors are common in general practice and hospital inpatients [76, 77]. The hospital environment is particularly prone to error-provoking conditions. Hospital wards may be busy or understaffed, and clinicians may inadequately supervise the medication use process or fail to check important information. Tiredness and the need to multitask often interrupt critical processes, such as administration of medicines, cause adverse ramifications for patient safety [78]. For example, a study conducted in a Spanish tertiary-care hospital emergency department noted that medication errors occurred most fre- 
quently when medication were administered, especially during the afternoon or evening shift when staff were more tired [79].

Certain hospital specialties are associated with increased risk of medication administration error. In a prospective incident monitoring study conducted at a large Chinese tertiary hospital, the frequency of administration error during anaesthesia was $1.1 \%$. The largest categories of errors were omissions, incorrect doses and substitutions. Even then, substantially more respondents who claimed that they were not fully rested reported inattention as a contributing factor to errors compared to those who were fully rested [80].

\subsubsection{Some Ways to Ensure Medication Safety in High- Risk Situations}

\subsubsection{High-Risk Medications}

Both at local and global level, the purpose of identifying a list of high-alert medications is to determine which drugs require special safeguards to reduce the risk of errors and minimise harm that can occur in the different phases of the medication use process [71]. Simplifying and standardising the ordering, storage, preparation, and dispensing of high-risk medications is the main strategy to reduce the risk of errors from highrisk medicines. In the fifth edition of the Accreditation Standards for Hospitals, the Joint Commission International identified improving the safety of high-risk medications in hospitals as a key objective, paying particular attention on the development and implementation of processes to manage the safe use of concentrated electrolytes [81]. Concentrated electrolyte solutions should always be stored in a controlled environment to prevent selection error and inadvertent administration of undiluted solutions, which have contributed to fatal outcomes.

Healthcare professionals are also involved in ensuring safe prescription, administration and monitoring of high-risk medications. In this regard, drugs with a narrow therapeutic index, such as chemotherapeutics and orally active vitamin $\mathrm{K}$ antagonists, should be carefully dosed and monitored by clinicians, in order to perform dose adjustments when necessary. Indeed, even small increases in the concentration of these medications at their site of action, for example, due to pharmacological interaction or concomitant disease, may cause a significant increase in their effect, resulting in patient harm [64]. Therapeutic guidelines should be followed for drugs where dosing is complex and duration of therapy substantially increases the risk of toxicity, for example, aminoglycosides and opioids [70]. "Navigating opioids for chronic pain" is a tool that provides guidance on different opioids based on morphine equivalence to compare the relative potency of the different molecules [82]. The use of shelf reminders, auxiliary labels, checklists and automated alerts, better if built into information technology systems, is intended to improve information and stimulate the attention of the clinicians regarding high-risk medicines. A regular review of local and broader system incidents and near-misses and the use of prospective analysis and re-design of systems is fundamental to prevent reoccurrence of the same errors with these drugs [70].

\subsubsection{High-Risk Patients}

All patients should be supported by a prescribing team working in close partnership with other healthcare providers, to ensure that they are aware of the therapeutic objectives of the medications taken, their likely benefits and potential side effects [83]. Self-empowerment among patients is essential to promote medication safety, as they serve as the final barrier in preventing medication errors. For this purpose, the use of aide-memoire tools, such as WHO 5 Moments for Medication Safety, should be promoted especially among high-risk patients, their families and caregivers, at all levels of care and across all settings [84].

Among the paediatric population, improving medication safety across the spectrum of their medication use process remains an area of critical focus. In a prospective cohort study on prioritising strategies for preventing medication errors and ADEs in paediatric inpatients, computerised physician order entry with clinical decision sup- 
port systems, ward-based clinical pharmacists and improved communication among physicians, nurses, and pharmacists were identified as having the greatest potential to reduce medication errors [85]. While some advanced technologies, such as computerised physician order entry with clinical decision support systems, are increasingly adopted worldwide, others, including barcode administration systems and "SMART pumps" (i.e. infusion delivery systems that provide decision support for users), are only mainstream in the United States [86]. Technologies to improve medication safety that are still in the pipeline include mobile apps to assist each step of the medication management process from ordering to delivery in real time and workflow management systems.

In outpatient paediatrics, focus of interventions should be on the administration stage considering that parents, rather than patients or trained nurses, administer most medications. This process is error-prone, including parental confusion regarding the correct use of teaspoons, tablespoons, and dose cups. Supplementing the often-rushed information from physicians and pharmacists regarding drug administration with accurate Internet-based information on drugs or a personal consultation with an office-based pharmacist could be helpful [73].

In the elderly population, rational prescribing is a crucial step to avoid ADRs resulting from unnecessary drug use, incorrect drug choices, inappropriate dosing regimens and therapeutic duplications [74]. Lists have been derived from consensus opinion to guide clinicians, and primarily general practitioners, about appropriate prescriptions for older people, including the Beers Criteria and STOPP/START tool $[87,88]$. While the use of such criteria would reduce the risk of wrong prescription in older people, it is most effective if supplemented with periodic medication reviews, as reduction in the absolute number of prescribed medications, particularly non-indicated items, can minimise the risk of ADRs [74]. Multidisciplinary cooperation between nurses, physicists and pharmacists is essential in this aspect. By mak- ing medical care plans together, errors associated with incorrect doses and noncompliance with regulations and laws can be prevented more effectively [89].

There is a paucity of information on medication safety during pregnancy. This underscores the important role healthcare providers play as trusted sources of information for women during this vital stage of their life. Interactions between women of childbearing age and their physicians and pharmacists will influence the decisions they make about medication use. Strategic messaging and improved informational resources could help maximise the effectiveness of these interactions by ensuring that women receive the clear, credible, and comprehensive information about medication risks during pregnancy at the right time [90].

\subsubsection{High-Risk Contexts}

The working environment in healthcare facilities, primarily hospital settings, are often suboptimal with fluctuations in workload, staffing absences, missing medical records, distractions, and time pressures. Thus, prescribers should be equipped with the knowledge, skills and resilience to cope with these eventualities [91]. Various strategies can be taken to mitigate inherent risks in high-risk situations. As an example, in the hospital setting, preparing and administering intravenous medications is particularly complex, error prone and dangerous. Mitigation of this risk entails conduct of error checking at each stage of the preparation. The use of pre-prepared injections may also help by eliminating errors in the reconstitution of drug and diluent [92]. Another risk reduction strategy is the implementation of electronic prescription. A recent systematic review and meta-analysis of 38 prospective interventional studies found that hospital-based electronic prescription strategies reduced medication errors, dosing errors and ADEs. Although the available evidence was heterogeneous and mainly represented by non-randomised studies, it provides early data to justify implementation and further evaluation of computerised strategies [93]. 


\subsection{Final Recommendations and Conclusions}

The complexity and vastness of the healthcare system as well as the rapid advancement in pharmacotherapy render medication safety challenging to achieve. A patient can now be seen by multiple prescribers in multiple facilities and started on multiple medications, some of which are high-risk. Healthcare workers are also working in an increasingly siloed environment, focusing on the specialisation of their unit, resulting in fragmented information exchange and lack of inter-departmental cooperation. All these factors increase the probability and propensity for unintentional medication errors to occur. Therefore, it is now vital for the next generation of healthcare professionals to appreciate the magnitude of the challenges faced in ensuring medication safety, using the current strategies as a reference to devise their own innovative solutions.

As a recap of the chapter, transitions of care is a major contributor to medication discrepancies. A lack of information sharing among healthcare professionals detailing medication changes when patients transfer from one hospital to another or between different setting of care, and inadequate patient health literacy are the main causes for this lapse in medication safety. Focusing on medication reconciliation, information clarity during care transition, as well as patient engagement and empowerment are keys to alleviate this issue.

The use of multiple medications or polypharmacy is a rising trend. This will inevitably increase medication-related adverse events leading to patient harm. Various measures have been taken to promote rationale prescribing, especially among elderly patients as well as to reduce inappropriate polypharmacy. Conducting robust research in this area is a priority, as there is insufficient evidences that current polypharmacyrelated interventions significantly improve patients' clinical outcomes. Multifaceted interventions involving multiple stakeholders and health system changes should be the focus of future research to ensure medication safety in this aspect of care.
Some situations, including patients, specific medications and contexts of care, are associated with higher inherent safety risks. High-risk medications are often those with narrow therapeutic index and high potency, whereas some patient segments, especially children, geriatrics and pregnant women, are physiologically more vulnerable to errors. Chaotic and understaffed institutions, including poorly trained staff, also increase medication error risk. Use of alert systems, checklists and computerised technologies are strategies that can reduce the risk level. Safer hospital and primary care will be achievable when safety strategies and risk management skills are built into healthcare systems and practices of medication, safety and risk management is built into healthcare systems and processes.

\section{References}

1. World Health Organization. Patient safety: making health care safer. Geneva: World Health Organization; 2017.

2. World Health Organization. WHO global patient safety challenge: medication without harm. Geneva: World Health Organization; 2017.

3. About medication errors [website]. Rockville, MD: National Coordinating Council for Medication Error Reporting and Prevention; 2019. http://www.nccmerp.org/about-medication-errors. Accessed 31 Oct 2019.

4. 10 facts on Patient Safety [website]. Geneva: World Health Organization; 2019. https://www.who.int/ features/factfiles/patient_safety/en/. Accessed 31 Oct 2019.

5. Aitken M, Gorokhovich L. Advancing the responsible use of medicines: applying levers for change. Parsippany, NJ: IMS Institute for Healthcare Informatics; 2012.

6. World Health Organization. Medication safety in transitions of care. Geneva: World Health Organization; 2019.

7. Coleman EA, Smith JD, Raha D, Min S-J. Posthospital medication discrepancies: prevalence and contributing factors. Arch Intern Med. 2005;165(16):1842-7.

8. Eng JA, Steinman MA. Changing chronic medications in hospitalized patients - bridging the inpatientoutpatient divide. J Hosp Med. 2014;9(5):332-3.

9. Cornish PL, Knowles SR, Marchesano R, Tam V, Shadowitz S, Juurlink DN, et al. Unintended medication discrepancies at the time of hospital admission. Arch Intern Med. 2005;165:424-9. 
10. Tam VC, Knowles SR, Cornish PL, Fine N, Marchesano R, Etchells EE. Frequency, type and clinical importance of medication history errors at admission to hospital: a systematic review. CMAJ. 2005;173(5):510-5.

11. Shah C, Hough J, Jani Y. Collaborative audit across England on the quality of medication related information provided when transferring patients from secondary care to primary care and the subsequent medicines reconciliation in primary care. London: NHS Specialist Pharmacy Service; 2016.

12. Lehnbom EC, Stewart MJ, Manias E, Westbrook JI. Impact of medication reconciliation and review on clinical outcomes. Ann Pharmacother. 2014;48(10):1298-312.

13. World Health Organization. The high $5 \mathrm{~s}$ project: interim report. Geneva: World Health Organization; 2014.

14. Otero MJ, Schmitt E. Clarifying terminology for adverse drug events. Ann Intern Med. 2005;142(1):77.

15. Mueller SK, Sponsler KC, Kripalani S, Schnipper JL. Hospital-based medication reconciliation practices: a systematic review. Arch Intern Med. 2012;172(14):1057-69.

16. World Health Organization. Transitions of care: technical series on safer primary care. Geneva: World Health Organization; 2016.

17. Gleason KM, Brake H, Agramonte V, Perfetti C. Medications at transitions and clinical handoffs (MATCH) toolkit for medication reconciliation. Agency for Healthcare Research and Quality: Rockville, MD; 2012.

18. World Health Organization. Global diffusion of eHealth: making universal health coverage achievable. Report of the third global survey on eHealth. Geneva: World Health Organization; 2016.

19. Ammenwerth E, Schnell-Inderst P, Hoerbst A. The impact of electronic patient portals on patient care: a systematic review of controlled trials. J Med Internet Res. 2012;14(6):e162.

20. Mekonnen AB, Abebe TB, McLachlan AJ, Brien JA. Impact of electronic medication reconciliation interventions on medication discrepancies at hospital transitions: a systematic review and metaanalysis. BMC Med Inform Decis Mak. 2016;16:112.

21. Coleman EA, Smith JD, Frank JC, Min SJ, Parry C, Kramer AM. Preparing patients and caregivers to participate in care delivered across settings: the Care Transitions Intervention. J Am Geriatr Soc. 2004;52(11):1817-25.

22. Kristeller J. Transition of care: pharmacist help needed. Los Angeles, CA: SAGE Publications.

23. McCray AT. Promoting health literacy. J Am Med Inform Assoc. 2005;12(2):152-63.

24. Ontario Hospital Association. Recommended patient experience surveys. Toronto, ON: Ontario Hospital Association; 2019.

25. Canadian Patient Safety Institute. Engaging patients in patient safety: a Canadian guide. Edmonton, AB: Canadian Patient Safety Institute; 2018.
26. Duerden M, Avery T, Rupert P. Polypharmacy and medicines optimisation: making it safe and sound. London: The King's Fund; 2013.

27. Molokhia M, Majeed A. Current and future perspectives on the management of polypharmacy. BMC Fam Pract. 2017;18(1):70.

28. Hajjar ER, Cafiero AC, Hanlon JT. Polypharmacy in elderly patients. Am J Geriatr Pharmacother. 2007;5(4):345-51.

29. Sergi G, Rui MD, Sarti S, Manzato E. Polypharmacy in the elderly. Drugs Aging. 2011;28(7):509-18.

30. Masnoon N, Shakib S, Kalisch-Ellett L, Caughey GE. What is polypharmacy? A systematic review of definitions. BMC Geriatr. 2017;17(1):230.

31. Bushardt RL, Massey EB, Simpson TW, Ariail JC, Simpson KN. Polypharmacy: misleading, but manageable. Clin Interv Aging. 2008;3(2):383-9.

32. Gillette C, Prunty L, Wolcott J, Broedel-Zaugg K. A new lexicon for polypharmacy: implications for research, practice, and education. Res Soc Adm Pharm. 2015;11(3):468-71.

33. Rankin A, Cadogan CA, Patterson SM, Kerse N, Cardwell CR, Bradley $\mathrm{MC}$, et al. Interventions to improve the appropriate use of polypharmacy for older people. Cochrane Database Syst Rev. 2018;(9):CD008165.

34. Hovstadius B, Petersson G. Factors leading to excessive polypharmacy. In: Holmes HM, editor. Clinics in geriatric medicine, vol. 28. Elsevier Inc: Philadelphia, PA; 2012. p. 159.

35. Elmståhl SL, Linder H. Polypharmacy and inappropriate drug use among older people-a systematic review. Healthy Aging Clin Care Elderly. 2013;5:1.

36. Midão L, Giardini A, Menditto E, Kardas P, Costa E. Polypharmacy prevalence among older adults based on the survey of health, ageing and retirement in Europe. Arch Gerontol Geriatr. 2018;78:213-20.

37. Lim LM, McStea M, Chung WW, Nor Azmi N, Abdul Aziz SA, Alwi S, et al. Prevalence, risk factors and health outcomes associated with polypharmacy among urban community-dwelling older adults in multi-ethnic Malaysia. PLoS One. 2017;12(3):e0173466.

38. Jokanovic N, Tan ECK, Dooley MJ, Kirkpatrick CM, Bell JS. Prevalence and factors associated with polypharmacy in long-term care facilities: a systematic review. J Am Med Directors Assoc. 2015;16(6):535e1-e12.

39. Sheikh A, Dhingra-Kumar N, Kelley E, Kieny MP, Donaldson LJ. The third global patient safety challenge: tackling medication-related harm. Bull World Health Organ. 2017;95(8):546-A.

40. Garfinkel D, Ilhan B, Bahat G. Routine deprescribing of chronic medications to combat polypharmacy. Ther Adv Drug Saf. 2015;6(6):212-33.

41. World Health Organisation. Medication safety in polypharmacy. Geneva: World Health Organisation; 2019.

42. Barnett K, Mercer SW, Norbury M, Watt G, Wyke S, Guthrie B. Epidemiology of multimorbid- 
ity and implications for health care, research, and medical education: a cross-sectional study. Lancet. 2012;380(9836):37-43.

43. Fried TR, O'Leary J, Towle V, Goldstein MK, Trentalange M, Martin DK. Health outcomes associated with polypharmacy in community-dwelling older adults: a systematic review. J Am Geriatr Soc. 2014;62(12):2261-72.

44. Gnjidic D, Le Couteur DG, Kouladjian L, Hilmer SN. Deprescribing trials: methods to reduce polypharmacy and the impact on prescribing and clinical outcomes. Clin Geriatr Med. 2012;28(2):237-53.

45. Charlesworth CJ, Smit E, Lee DSH, Alramadhan F, Odden MC. Polypharmacy among adults aged 65 years and older in the United States: 1988-2010. J Gerontol A. 2015;70(8):989-95.

46. Morin L, Johnell K, Laroche M-L, Fastbom J, Wastesson JW. The epidemiology of polypharmacy in older adults: register-based prospective cohort study. Clin Epidemiol. 2018;10:289-98.

47. Johansson T, Abuzahra ME, Keller S, Mann E, Faller B, Sommerauer C, et al. Impact of strategies to reduce polypharmacy on clinically relevant endpoints: a systematic review and meta-analysis. $\mathrm{Br} \mathrm{J}$ Clin Pharmacol. 2016;82(2):532-48.

48. Alldred DP, Kennedy MC, Hughes C, Chen TF, Miller P. Interventions to optimise prescribing for older people in care homes. Cochrane Database Syst Rev. 2016;(2):CD009095.

49. Jokanovic N, Wang KN, Dooley MJ, Lalic S, Tan ECK, Kirkpatrick CM, et al. Prioritizing interventions to manage polypharmacy in Australian aged care facilities. Res Soc Adm Pharm. 2017;13(3):564-74.

50. Scottish Government Polypharmacy Model of Care Group. Polypharmacy guidance, realistic prescribing. 3rd ed. Edinburgh: Scottish Government; 2018.

51. Fick DM, Cooper JW, Wade WE, Waller JL, Maclean JR, Beers MH. Updating the Beers criteria for potentially inappropriate medication use in older adults: results of a US Consensus Panel of Experts. JAMA Intern Med. 2003;163(22):2716-24.

52. Burt J, Elmore N, Campbell SM, Rodgers S, Avery AJ, Payne RA. Developing a measure of polypharmacy appropriateness in primary care: systematic review and expert consensus study. BMC Med. 2018;16(1):91.

53. Hatah E, Braund R, Tordoff J, Duffull SB. A systematic review and meta-analysis of pharmacist-led feefor-services medication review. Br J Clin Pharmacol. 2014;77(1):102-15.

54. Messerli M, Blozik E, Vriends N, Hersberger KE. Impact of a community pharmacist-led medication review on medicines use in patients on polypharmacy - a prospective randomised controlled trial. BMC Health Serv Res. 2016;16(1): 145.

55. Jódar-Sánchez F, Malet-Larrea A, Martín JJ, GarcíaMochón L, López del Amo MP, Martínez-Martínez $\mathrm{F}$, et al. Cost-utility analysis of a medication review with follow-up service for older adults with poly- pharmacy in community pharmacies in Spain: the conSIGUE Program. PharmacoEconomics. 2015;33(6):599-610.

56. Malet-Larrea A, Goyenechea E, García-Cárdenas V, Calvo B, Arteche JM, Aranegui P, et al. The impact of a medication review with follow-up service on hospital admissions in aged polypharmacy patients. $\mathrm{Br} \mathrm{J}$ Clin Pharmacol. 2016;82(3):831-8.

57. Viswanathan M, Kahwati LC, Golin CE, Blalock SJ, Coker-Schwimmer E, Posey R, et al. Medication therapy management interventions in outpatient settings: a systematic review and meta-analysis. JAMA Intern Med. 2015;175(1):76-87.

58. Muth C, Blom JW, Smith SM, Johnell K, GonzalezGonzalez AI, Nguyen TS, et al. Evidence supporting the best clinical management of patients with multimorbidity and polypharmacy: a systematic guideline review and expert consensus. J Intern Med. 2019;285(3):272-88.

59. Rieckert A, Teichmann A-L, Drewelow E, Kriechmayr C, Piccoliori G, Woodham A, et al. Reduction of inappropriate medication in older populations by electronic decision support (the PRIMA-eDS project): a survey of general practitioners' experiences. J Am Med Inform Assoc. 2019;26:1323.

60. Scott IA, Hilmer SN, Reeve E, Potter K, Le Couteur $\mathrm{D}$, Rigby D, et al. Reducing inappropriate polypharmacy: the process of deprescribing. JAMA Intern Med. 2015;175(5):827-34.

61. Thompson W, Farrell B. Deprescribing: what is it and what does the evidence tell us? Can J Hosp Pharm. 2013;66(3):201-2.

62. Ulley J, Harrop D, Ali A, Alton S, Fowler Davis S. Deprescribing interventions and their impact on medication adherence in community-dwelling older adults with polypharmacy: a systematic review. BMC Geriatr. 2019;19(1):15

63. Stewart D, Mair A, Wilson M, Kardas P, Lewek P, Alonso A, et al. Guidance to manage inappropriate polypharmacy in older people: systematic review and future developments. Expert Opin Drug Saf. 2017;16(2):203-13.

64. Medication safety in high-risk situations. Geneva: World Health Organisation; 2019. https://www. who.int/patientsafety/medication-safety/HighRisk. pdf?ua=1. Accessed 15 Oct 2019.

65. Wood ME, Lapane KL, van Gelder MMHJ, Rai D, Nordeng HME. Making fair comparisons in pregnancy medication safety studies: an overview of advanced methods for confounding control. Pharmacoepidemiol Drug Saf. 2018;27(2):140-7.

66. Sheikh A, Rudan I, Cresswell K, Dhingra-Kumar N, Tan ML, Hakkinen ML, et al. Agreeing on global research priorities for medication safety: an international prioritisation exercise. $J$ Glob Health. 2019;9(1):010422.

67. American Pharmacists Association. Medication errors. 2nd ed. Washington, DC: American Pharmacists Association; 2007. 
68. Alanazi MA, Tully MP, Lewis PJ. A systematic review of the prevalence and incidence of prescribing errors with high-risk medicines in hospitals. J Clin Pharm Ther. 2016;41(3):239-45.

69. Saedder EA, Brock B, Nielsen LP, Bonnerup DK, Lisby M. Identifying high-risk medication: a systematic literature review. Eur J Clin Pharmacol. 2014;70(6):637-45.

70. Clinical Excellence Commission. High-risk medicines management policy. Sydney: NSW Ministry of Health; 2015. https://www1.health.nsw.gov.au/pds/ ActivePDSDocuments/PD2015_029.pdf. Accessed 15 Oct 2019.

71. ISMP. High-alert medications. Institute for Safe Medication Practices: Horsham, PA; 2019. http:// www.ismp.org/Tools/highAlertMedicationLists.asp. Accessed 15 Oct 2019.

72. Rinke ML, Bundy DG, Velasquez CA, Rao S, Zerhouni Y, Lobner K, et al. Interventions to reduce pediatric medication errors: a systematic review. Pediatrics. 2014;134(2):338-60.

73. Kaushal R, Jaggi T, Walsh K, Fortescue EB, Bates DW. Pediatric medication errors: what do we know? What gaps remain? Ambul Pediatr. 2004;4(1):73-81.

74. Hubbard RE, O'Mahony MS, Woodhouse KW. Medication prescribing in frail older people. Eur J Clin Pharmacol. 2013;69(3):319-26.

75. Trønnes JN, Lupattelli A, Nordeng H. Safety profile of medication used during pregnancy: results of a multinational European study. Pharmacoepidemiol Drug Saf. 2017;26(7):802-11.

76. Avery A, Barber N, Ghaleb M, Franklin BD, Armstrong S, Crowe S, et al. Investigating the prevalence and causes of prescribing errors in general practice: the PRACtICe study. London: General Medical Council; 2012. https://www.gmcuk.org//media/about/ investigatingtheprevalenceandcausesofprescribingerrorsingeneralpracticethepracticestudyreoprtmay 2012. pdf?la=en\&hash $=62 \mathrm{C} 1821 \mathrm{CA} 5 \mathrm{CCC} 5 \mathrm{~A} 4868 \mathrm{~B} 86 \mathrm{~A} 83$ FEDE14283686C29. Accessed 15 Oct 2019.

77. Dornan T, Ashcroft D, Heathfield H, Lewis P, Miles J, Taylor D, et al. An in-depth investigation into causes of prescribing errors by foundation trainees in relation to their medical education: EQUIP study. London: General Medical Council; 2009. https://www.gmcuk. org/FINAL_Report_prevalence_and_causes_of_prescribing_errors.pdf_28935150.pdf. Accessed 15 Oct 2019.

78. Westbrook JI, Woods A, Rob MI, Dunsmuir WT, Day RO. Association of interruptions with an increased risk and severity of medication administration errors. Arch Intern Med. 2010;170(8):683-90.

79. Consuelo-Estrada JR, Gaona-Valle LS, PortilloRodríguez O. Lesiones por causa externa en el servicio de urgencias de un hospital en un periodo de cinco años. Gac Med Mex. 2018;154(3):302-9.

80. Zhang Y, Dong YJ, Webster CS, Ding XD, Liu $\mathrm{XY}$, Chen WM, et al. The frequency and nature of drug administration error during anaesthesia in a Chinese hospital. Acta Anaesthesiol Scand. 2013;57(2):158-64.

81. Joint Commission International Standards for Hospital. 5th Edition. 2014. https://www.jointcommissioninternational.org/assets/3/7/Hospital-5EStandards-Only-Mar2014.pdf. Accessed 15 Oct 2019.

82. University of Toronto, Institute for Safe Medication Practices Canada, Physicians for Responsible Opioid Prescribing. Navigating opioids for chronic pain. Toronto, ON: Institute for Safe Medication Practices Canada; 2019. https://www.ismpcanada.org/ download/OpioidStewardship/navigating-opioids11x17-canada.pdf. Accessed 15 Oct 2019.

83. Routledge PA. Safe prescribing: a titanic challenge. Br J Clin Pharmacol. 2012;74(4):676-84.

84. 5 Moments for medication safety. In: Patient Safety. Geneva: World Health Organization; 2019. https://www.who.int/patientsafety/ medicationsafety/5moments/en/. Accessed 15 Oct 2019.

85. Fortescue EB, Kaushal R, Landrigan CP, McKenna KJ, Clapp MD, Federico F, et al. Prioritizing strategies for preventing medication errors and adverse drug events in pediatric inpatients. Pediatrics. 2003;111(4 Pt 1):722-9.

86. Kahn S, Abramson EL. What is new in paediatric medication safety? Arch Dis Child. 2019;104(6):596-9.

87. Beers MH, Ouslander JG, Rollingher I, Reuben DB, Brooks J, Beck JC. Explicit criteria for determining inappropriate medication use in nursing home residents. UCLA Division of Geriatric Medicine. Arch Intern Med. 1991;151(9):1825-32.

88. Gallagher P, O'Mahony D. STOPP (Screening Tool of Older Persons' potentially inappropriate Prescriptions): application to acutely ill elderly patients and comparison with Beers' criteria. Age Ageing. 2008;37(6):673-9.

89. Metsälä E, Vaherkoski U. Medication errors in elderly acute care-a systematic review. Scand J Caring Sci. 2014;28(1):12-28.

90. Lynch MM, Amoozegar JB, McClure EM, Squiers LB, Broussard CS, Lind JN, et al. Improving safe use of medications during pregnancy: the roles of patients, physicians, and pharmacists. Qual Health Res. 2017;27(13):2071-80.

91. Maxwell SRJ, Webb DJ. Improving medication safety: focus on prescribers and systems. Lancet. 2019;394(10195):283-5.

92. McDowell SE, Mt-Isa S, Ashby D, Ferner RE. Where errors occur in the preparation and administration of intravenous medicines: a systematic review and Bayesian analysis. Qual Saf Health Care. 2010;19(4):341-5.

93. Roumeliotis N, Sniderman J, Adams-Webber T, Addo $\mathrm{N}$, Anand V, Rochon P, et al. Effect of electronic prescribing strategies on medication error and harm in hospital: a systematic review and meta-analysis. J Gen Intern Med. 2019;34(10):2210-23. 
Open Access This chapter is licensed under the terms of the Creative Commons Attribution 4.0 International License (http://creativecommons.org/licenses/by/4.0/), which permits use, sharing, adaptation, distribution and reproduction in any medium or format, as long as you give appropriate credit to the original author(s) and the source, provide a link to the Creative Commons license and indicate if changes were made.

The images or other third party material in this chapter are included in the chapter's Creative Commons license, unless indicated otherwise in a credit line to the material. If material is not included in the chapter's Creative Commons license and your intended use is not permitted by statutory regulation or exceeds the permitted use, you will need to obtain permission directly from the copyright holder.

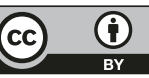

